\title{
Transferências de renda e mudança social no Brasil: um olhar sobre o Programa Bolsa Família
}

\author{
Vanuza Maria Pontes Sena \\ Cristina Pereira de Aranjo
}

\begin{abstract}
Resumo
$\mathrm{Na}$ lógica de reprodução capitalista do espaço, as desigualdades se concretizam no contexto do arranjo urbano. Quanto maiores forem as disparidades socioeconômicas entre as classes sociais, maiores serão as diferenças na qualidade de vida das pessoas. Não obstante a diversidade de instrumentos existentes, as políticas sociais são hoje concebidas primordialmente nos países em desenvolvimento, inclusive no Brasil, por meio de transferências monetárias de renda. À vista disso, este estudo tem como proposta analisar as políticas de transferência de renda no Brasil, com ênfase no Programa Bolsa Família, durante os governos de Luiz Inácio Lula da Silva e Dilma Rousseff, procurando mostrar a relevância que esse programa teve na sua dimensão social. Para tanto, realizou-se revisão bibliográfica, pesquisa documental e levantamento estatístico, sobretudo, junto a fontes oficiais brasileiras. Os principais resultados revelam que as iniciativas de transferência de renda, como o Programa Bolsa Família, consolidaram-se como uma importante estratégia do Sistema de Proteção Social, visto que contribuíram para a diminuição da incidência da pobreza sobre a população brasileira e para a queda da desigualdade de renda no período supracitado.
\end{abstract}

Palavras-chave | Bolsa Família; Brasil; desigualdade; pobreza; transferência de renda.

Classificação JEL | D63 H53 I38

Income transference and social change in Brazil: a look at the Bolsa Familia Program

\begin{abstract}
In the logic of capitalist reproduction of space, inequalities are certainly concretized in the context of the urban arrangement. Therefore, the greater the socioeconomic disparities among social classes, the greater the differences in people's quality of life. Despite the diversity of range of instruments, social public policies today are conceived primarily in developing countries, and in Brazil, through monetary income transfers. Because of this, the study aims to develop an analysis of income transfer policies in Brazil, with emphasis on the Bolsa Família Program,
\end{abstract}


during the governments of Presidents Luiz Inácio Lula da Silva and Dilma Rousseff, seeking to show the relevance that this program had in the social dimension. To this end, a literature review and documentary research were carried out, especially in sources of statistics and studies from official Brazilian agencies. The main results reveal that income transfer initiatives, such as the Bolsa Família Program, have been consolidated as an important strategy of the Social Protection System since they have contributed to the reduction of poverty among the Brazilian population and to the decreasing of income inequality in the aforementioned period.

Keywords | Bolsa Família; Brazil; income transfer; inequality; poverty.

JEL Classification | D63 H53 I38

\section{Transferencia de ingreso y cambio social en Brasil: una mirada al Programa Bolsa Familia}

\section{Resumen}

En la lógica de la reproducción capitalista del espacio, las desigualdades son plasmadas en el territorio. Cuánto mayores sean las disparidades socioeconómicas entre clases sociales, mayores serán las diferencias en la calidad de vida de las personas. A pesar de la diversidad de instrumentos existentes, las políticas sociales se conciben actualmente principalmente en los países en desarrollo, incluido Brasil, a través de transferencias monetarias de ingreso. En este contexto, esta investigación tiene como propuesta analizar las políticas de transferencia de ingresos en Brasil, con énfasis en el Programa Bolsa Familia, durante los gobiernos de Luiz Inácio Lula da Silva y Dilma Rousseff, procurando enfatizar la relevancia de este programa en la dimensión social. Por tanto, se realizó una revisión bibliográfica, una investigación documental y un levantamiento estadístico, en especial, de fuentes oficiales brasileñas. Los principales resultados revelan que las iniciativas de transferencia de ingresos, como el Programa Bolsa Familia, se consolidaron como una importante estrategia del Sistema de Protección Social, pues contribuyeron para la reducción de la pobreza de la población brasilera y para la disminución de la desigualdad económica en el período analizado.

Palabras clave | Bolsa Familia; Brasil; desigualdad; pobreza; transferencia de ingresos.

Clasificación JEL | D63 H53 I38

\section{Introdução}

A distribuição de renda no Brasil é historicamente desigual, originária de processos geopolíticos externos e internos, que vão desde os processos de colonização e escravidão até a forma de estruturação do território nacional que conduziu o país a uma divisão territorial do trabalho que fragmenta sul e norte, litoral e interior.

Uma vez que esse problema não é vivenciado somente pelo Brasil, mas que é inerente à lógica de acumulação do capital, há que se considerar que no âmbito 
internacional também existem programas de combate à fome e à pobreza. Nessa perspectiva, no Brasil dos governos Lula e Dilma, as políticas sociais, especialmente as de transferências de renda, encontraram forte desígnio, sendo objeto de diversos estudos que mostram a queda da desigualdade de renda, da pobreza e extrema pobreza.

Parte-se do reconhecimento de que o Brasil ainda está entre os países mais desiguais do mundo, situando-se na sétima posição, conforme o Relatório de Desenvolvimento Humano (RDH) de 2019, do Programa das Nações Unidas para o Desenvolvimento (PNDU). No entanto, é legítimo admitir que, no período de 2003 a 2015, muito se avançou em políticas sociais voltadas à proteção das camadas menos favorecidas da população e à expansão do mercado interno de consumo popular. À luz desses fatos históricos, este estudo tem como objetivo analisar os efeitos das políticas de transferências de renda, especialmente do Programa Bolsa Família (PBF), tendo em vista sua contribuição na minoração da pobreza e da desigualdade social no Brasil durante os governos Lula-Dilma.

Importante destacar que, neste estudo, busca-se abordar o fenômeno da pobreza numa perspectiva multidimensional, ou seja, levando-se em consideração não só a falta de renda, mas todos os demais elementos (saúde, educação, infraestrutura, dentre outros) necessários para um indivíduo desenvolver uma vida digna, constituída de liberdade.

Para tanto, parte-se de uma revisão bibliográfica da literatura especializada e da compilação de dados secundários fornecidos pelo Instituto Brasileiro de Geografia e Estatística (IBGE) e pelo Instituto de Pesquisa Econômica Aplicada (IPEA), além do Ministério do Desenvolvimento Social e Combate à Fome (MDS).

Além desta introdução e das considerações finais, o artigo é composto por três seções dispostas da seguinte forma: a primeira aborda a trajetória dos sistemas de proteção social no nível mundial tomando-se como referência países europeus, os Estados Unidos e países latino-americanos; a segunda, por seu turno, apresenta e discute a trajetória do sistema de proteção social no Brasil, destacando suas diferentes fases; e, por fim, a última sessão discute sobre a assistência social no governo Lula-Dilma, com ênfase no Programa Bolsa Família.

\section{Políticas assistenciais no mundo}

O sistema de proteção social surge a partir do confronto de interesses entre o grande capital e a grande massa trabalhadora frente ao novo modo de acumulação disseminado pelo mundo após a Segunda Guerra. O Estado, o grande capital e os sindicatos selaram o acordo do novo modo de regulamentação do regime fordista de acumulação, tendo no Welfare State o colchão de proteção social dado como 
moeda de troca para que a grande massa trabalhadora aderisse de vez ao sistema de produção em massa que se impunha.

O Welfare State, ou Estado de Bem-Estar Social, apresenta-se, então, como resposta às mudanças ocorridas na sociedade, no sentido da garantia de melhores condições de vida e bem-estar da população. Os programas de renda mínima, por sua vez, aparecem e se desenvolvem em meados do século XX nos países desenvolvidos articulados aos Estados de Bem-Estar Social.

[...] surgem como solução para a crise do Welfare State, juntamente com os processos de reestruturação produtiva e globalização como mecanismos que possam dar conta das transformações provocadas no mundo do trabalho, uma vez que estes afetaram negativamente a população mais frágil e vulnerável de cada país, evitando o aumento desenfreado das desigualdades sociais (SILVA; YAZBEK; GIOVANNI, 2014, p. 44).

Suplicy (2013) apresenta algumas experiências de sistemas de renda mínima garantidos em países como Dinamarca (1933), Reino Unido (1948), Alemanha (1961), Bélgica (1974), Irlanda (1977), Luxemburgo (1986) e França (1988). Destaca, ainda, no ano de 1990, as experiências ocorridas em diversas províncias da Espanha (Andaluzia, Aragón, Astúrias, Catalunha, Galícia, Múrcia, Navarra e no País Basco) e, em 1996, em Portugal. Essas experiências remontam ao novo caráter da proteção social disseminado a partir da década de 1930. O autor reforça que esses países introduziram maneiras de garantir uma renda mínima, seja na forma de benefícios às crianças, de auxílios às famílias com crianças dependentes, de suporte de renda: aos idosos, aos inválidos e aos que ganham pouco; de seguro-desemprego, chegando até a complexos sistemas de seguridade social.

Embora alguns poucos países já tivessem adotado programas de garantia de renda mínima anteriormente, foi no período do pós-guerra que a maior parte das nações europeias começou a adotar políticas sociais compostas por este tipo de mecanismo. Em 1986, foi fundada a Rede Europeia da Renda Básica - Basic Income European Network (BIEN), com a finalidade de defender a instituição de uma renda básica universal, ou seja, o direito de todas as pessoas incondicionalmente receberem uma soma suficiente para as suas necessidades (SUPLICY, 2013).

De acordo com Lavinas e Varsano (1998), a instituição da renda mínima garantida foi prevista na Carta Social, adotada em 1989 pelos países membros da União Europeia, com exceção da Inglaterra - que já tinha sua própria experiência de programa desta natureza desde 1948, quando implantou a National Assistance Act (Lei de Assistência Nacional), um programa de renda mínima para todas as famílias que atendia às necessidades de subsistência e complementava o sistema ampliado de proteção social. 
De forma distinta ao que ocorreu na Europa, na América Latina as políticas sociais foram mais desenvolvidas nos países com maior tradição democrática, como Uruguai e Costa Rica. Existiram, ainda, aqueles países que se estabeleceram com um perfil contributivo: foram os casos de Brasil e Argentina, que começaram a traçar essas políticas na primeira metade do século passado durante os governos progressistas de Getúlio Vargas e Juan Perón. O legado garantia direitos amplos, porém, restritos a grupos específicos de trabalhadores formais e tinham como principais áreas de política de proteção as pensões, os serviços de saúde e subsídio de produtos (THOMÉ, 2013).

Ao identificar as iniciativas dos programas na América Latina, Suplicy (2013) faz referência ao Assignación Familiar, instituído no Uruguai, Chile e Argentina, cuja finalidade previa uma complementação de renda aos trabalhadores com crianças em idade escolar. Já a Venezuela instituiu, em 1989, o programa Bolsa Escolar para as crianças de famílias carentes que estivessem frequentando escola, até o limite de três crianças por família, o que foi substituído pelo Programa de Subsídio Familiar, em 1996.

No caso dos Estados Unidos, a criação de programas sociais ocorreu a partir do Ato de Seguridade Social, formulado pelo governo de Franklin D. Roosevelt em 1935, quando foi instituído o Programa de Auxílio às Famílias com Crianças Dependentes - Aid for Families with Dependent Chidren (AFDC). O programa concedia um complemento financeiro às famílias com renda abaixo de um patamar considerado de subsistência. Em 1974, foi criado o Crédito Fiscal por Remuneração Recebida - Eamed Income Tax Credit (EITC), destinado a famílias com emprego e filhos pequenos. A intenção era gerar um imposto de renda negativo para as famílias que percebessem uma remuneração abaixo de um teto estabelecido. Ou seja, ao invés de pagar impostos, a família receberia uma contribuição do Estado para alcançar um valor mínimo que fosse considerado digno para sua subsistência (SUPLICY, 2013).

Atinente à trajetória do sistema de proteção social nos países europeus e Estados Unidos, verifica-se uma articulação das políticas visando à reprodução de uma ordem social mais eficiente, cabendo aos Estados disponibilizarem os serviços sociais básicos e a garantia de acesso aos mesmos por todos os cidadãos. Já na América Latina e, em particular, no Brasil, as políticas de cunho social não compactuaram da mesma lógica do Welfare State, pois, nesses países, o planejamento e a articulação das políticas sociais raramente apresentaram objetivos de longo prazo e comprometimentos além dos sucessivos ciclos presidenciais. Embora se reconheça que os temas da desigualdade e da pobreza estivessem presentes nas agendas políticas nacionais, o que não significa, necessariamente, que se destinem recursos para o cumprimento dessas agendas.

Sob esse prisma, mais premente nos países em dependência geopolítica, Figueiredo (2013, p. 7) diz que a desigualdade social se torna "ineliminável" ao considerar a 
reprodução do capital, posto que esta assenta na acumulação. Com efeito, também os nexos causais da pobreza permanecem e são adensados cada vez mais pela conjuntura de crise que se põe na contemporaneidade às condições de reprodução do capital. Nessa perspectiva, essa problemática tem uma dimensão ainda mais agravada quando se trata de um país subdesenvolvido, ou melhor, em dependência geopolítica a partir do acordo entre elites, onde a manutenção da pobreza faz parte da lógica de reprodução e acumulação capitalista. É o que se pode observar na perspectiva histórica das políticas de transferência de renda no Brasil.

\section{Políticas públicas de transferências de renda no Brasil em perspectiva histórica}

No Brasil, o sistema de proteção social começa a dar sinais de constituição a partir da década de 1930 no governo de Getúlio Vargas, porém, com alcance limitado, posto que se destinava somente às economias ligadas ao setor urbano industrial. $\mathrm{O}$ então presidente da República, a fim de dar maior visibilidade à sua política, passou a atuar fortemente no campo previdenciário, abolindo, em 1930, o sistema de Caixas de Aposentadorias e Pensões (CAPs), instituído pela Lei no 4.682 (Lei Elói Chaves), de janeiro de 1923, que previa a criação de uma caixa para cada companhia ferroviária. No lugar das CAPs, foram criados diversos Institutos de Aposentadoria e Pensões (IAPs), marcando o início de uma nova fase na história do seguro social brasileiro. Em 1933, foram estendidos os benefícios às categorias de trabalhadores dos setores bancários, industriários e aos servidores do Estado. Em 1960, foi promulgada a Lei Orgânica da Previdência Social (LOPS), com o intuito de uniformizar os direitos dos segurados dos diversos institutos (SOUZA, 2005).

A primeira proposta sobre transferência de rendimentos mínimos foi feita em 1975 por Antônio Maria Silveira - primeiro economista brasileiro a propor a instituição de um Programa de Garantia de Renda Mínima (PGRM), por meio de um imposto de renda negativo, defendendo a necessidade da erradicação da pobreza mediante medidas de redistribuição de renda. Em 1978, Edmar Lisboa Bacha e Roberto Mangabeira Unger também argumentaram a favor do rendimento mínimo garantido por um imposto de renda negativo (SUPLICY, 2013).

No entanto, foi a partir da promulgação da Constituição Federal de 1988 (BRASIL, 2016) que, de fato, efetivou-se o reconhecimento de direitos sociais básicos e a ampliação da cidadania dos brasileiros. Aprovada em 5 de outubro, a Constituição Federal de 1988 trouxe uma nova concepção para a assistência social, inaugurando um padrão de proteção social afirmativo de direitos que superasse as práticas assistenciais e clientelistas, além do surgimento de novos movimentos populares. Essas garantias, por sua vez, não podem funcionar sem articulação com as demais políticas, de modo que é uma obrigação do Estado a sua efetivação. Como afirma Cabrera (2015, p. 112), “[...] considera-se um momento histórico no qual o Brasil a 
reconhece legalmente, como forma de compensar as desigualdades existentes e de garantir o mínimo de dignidade às pessoas".

Nessa perspectiva, com o advento da Constituição Federal de 1988 é que o sistema de seguridade social passaria a ganhar status de política pública. Conforme é estabelecido no art. 194 (BRASIL, 2016), a seguridade social é constituída por três políticas de proteção social: Saúde, Previdência Social e Assistência Social.

Como bem explica Bresser-Pereira (2013), a chamada "Constituição Cidadã" trouxe ideais progressistas e nacionais, ressaltando a criação do Sistema Único de Saúde (SUS) como um dos principais avanços conquistados.

[...] o compromisso com a democracia e com a afirmação dos direitos sociais, e um substancial aumento dos gastos públicos voltados para a educação, a saúde pública e os programas de renda mínima foram resultados dessa Constituição, assim como foi a grande descentralização de recursos para os municípios (BRESSER-PEREIRA, 2013, p. 271).

É, portanto, a partir da Constituição Federal de 1988 que se pode olhar para as políticas públicas de assistência social no Brasil. Nelas, destacam-se os programas de transferência de renda, compreendidos enquanto políticas de garantia e segurança de renda, nas quais critérios de elegibilidade e contrapartidas podem ser adotados na forma de contribuições ou de condicionalidades. De um modo geral, Mattei (2015) argumenta que esses programas são políticas focalizadas a partir de dados e informações socioeconômicas sobre as famílias e domićlios, destinando recursos monetários diretamente aos beneficiários, o que pode incluir, também, doações de alimentos e complementos nutricionais.

Os programas de transferência de renda vão se configurar como principal estratégia no contexto da política de assistência social do Sistema de Proteção Social. Entre 1995 e 2010, o gasto social federal passou de $\mathrm{R} \$ 234$ bilhões para $\mathrm{R} \$$ 638,5 bilhões, representando um aumento na ordem de $173 \%$. Este avanço foi mais tímido no período de 1995 a 2003, registrando um avanço de 46,7\% e robusto para o período seguinte, um aporte de 86\% para o intervalo de 2003 a 2010 (CAMPOS, 2015).

Para Campos (2015), a implementação de novos programas na área da previdência e assistência durante a década de 1990, fazendo jus à Constituição Federal de 1988, e a aceleração destes nos anos 2000, com a implementação de novos programas também na área do desenvolvimento urbano, associado à elevação real do saláriomínimo (sobretudo a partir de 2003), foram os responsáveis pelo aporte percebido que, em 1995, representava 11,2\% do PIB e, em 2003, saltou para 13\%, uma expansão de 1,7 ponto percentual (pp.) para o intervalo considerado. Para o período seguinte, o investimento em relação ao PIB foi ainda maior: de 2,6 pp. em sete anos, saindo de $13 \%$ para $15,5 \%$ do PIB. 
O que se avalia sobre a adoção dos programas de transferência de renda é que este se deu, majoritariamente, como estratégia para o processo de rompimento do ciclo vicioso da pobreza, ao qual grande parte da população brasileira (ainda) está condicionada, visto que a transferência monetária a indivíduos ou famílias que se encontrem em situação de vulnerabilidade social é associada a políticas de saúde, de educação e de trabalho (SILVA; YAZBEK; GIOVANNI, 2014).

É com o Projeto de Lei no 80/1991, do Senador Eduardo Suplicy (PT/SP), que o debate em torno dos Programas de Transferências de Renda assume a centralidade das discussões em torno dos mínimos sociais, com a proposição de instituir uma renda mínima garantida por meio de um imposto de renda negativo. Conforme o projeto, o programa beneficiaria, sob a forma de imposto de renda negativo, todas as pessoas que recebessem rendimentos brutos inferiores a 2,5 salários-mínimos efetivos na época. "O imposto de renda negativo corresponderia a 50\% da diferença entre aquele patamar e a renda da pessoa, no caso de a pessoa estar trabalhando, e $30 \%$ no caso de estar tendo rendimento nulo ou não estar exercendo atividade remunerada" (SUPLICY, 2013, p. 171).

Nessa nova fase, após promulgação da Constituição Federal de 1988, as primeiras experiências no tocante aos programas de transferência no Brasil ocorreram nos municípios de Campinas e Ribeirão Preto, os quais estavam mais focados na garantia de uma Renda Básica de Cidadania (RBC). Inspirados nas experiências desses municípios, no âmbito do Governo Federal, em 1993, implantou-se o Benefício de Prestação Continuada (BPC). Na sequência, em 1996, iniciou-se o Programa de Erradicação do Trabalho Infantil (Peti), em 1997, o Programa Comunidade Solidária e, em 1999, começaram a surgir os primeiros programas estaduais (SILVA, 2006; MATTEI, 2015).

Até 2002, período do governo do então presidente Fernando Henrique Cardoso (FHC), o Brasil já tinha implantado um conjunto de iniciativas e programas de transferência de renda (programas remanescentes) com objetivos e naturezas distintas. No governo FHC, os projetos de renda mínima no Brasil estruturavam-se em 12 programas: Bolsa Alimentação, Peti, Bolsa Escola, Auxílio Gás, Brasil Jovem, Abono Salarial, Bolsa Qualificação, Seguro Desemprego, Seguro Garantia Safra, Aposentadorias e Pensões Rurais, Benefício de Prestação Continuada e Renda Mínima Vitalícia.

A partir de 2003, no governo do presidente Luiz Inácio Lula da Silva, registra-se um crescimento das políticas de transferências de renda destinadas à população, destacando-se a construção de uma proposta para agregar os programas de transferência existentes, representada pela instituição do Programa Bolsa Família, que resultou da unificação dos seguintes programas: Bolsa Escola, Bolsa Alimentação, Auxílio Gás, Cartão Alimentação e o Programa de Erradicação do Trabalho Infantil (SILVA; YAZBEK; GIOVANNI, 2014). 
Como destaca Brandão (2017, p. 61), os governos de Lula e Dilma podem ser caracterizados como um período em que começou a ser constituída "uma plataforma social ou terreno de maior homogeneidade social, um patamar básico de cidadania, um colchão amortecedor e um chão de segurança social e de acesso a direitos individuais", visando à redução da pobreza e da exclusão social", com a possibilidade de ingresso e integração na sociedade moderna por parte das massas historicamente destituídas dos frutos do progresso no Brasil.

$\mathrm{O}$ aumento do direcionamento de recursos para políticas sociais verificado nesse período salta da ordem de $\mathrm{R} \$ 12,2$ bilhões em 2002 para $\mathrm{R} \$ 68$, 5 bilhões em 2014 (SILVA, LIMA, 2016), o que denota a relativa elevação desta área na prioridade do direcionamento de recursos por parte do fundo público, em grande medida estimulado pelo crescimento do Produto Interno Bruto (PIB). De acordo com Bresser-Pereira (2013), nos oito anos do governo Lula, entre 2003 e 2010, a taxa de crescimento do PIB e seu principal determinante, a taxa de investimento, aumentaram: a taxa de investimento foi de $17 \%$ para $19 \%$, e a de crescimento do PIB elevou de 2,5\% para cerca de 4,5\% (BRESSER-PEREIRA, 2013, p. 354).

Em 2011, no primeiro ano do governo da presidenta Dilma Rousseff, os números apontam para um processo robusto de redução da pobreza e da desigualdade social no Brasil, acompanhado da redução do desemprego, incremento do emprego formal com carteira de trabalho assinada, elevação da renda do trabalho e consequente ampliação do número de trabalhadores e de outros segmentos da população, como donas de casa, na Previdência Social (SILVA, LIMA, 2016). Mas, sem dúvida, foi o Programa Bolsa Família ${ }^{1}$ o carro-chefe da base assistencialista do governo e que permitiu a longevidade e o sucesso das demais políticas, como será visto a seguir.

\section{Assistência social no governo Lula-Dilma: um olhar sobre o Programa Bolsa Família}

Quando Lula assumiu o governo, em 2003, o país vivia um momento difícil de ameaça da volta da inflação, de aumento do desemprego, desprestígio internacional - um quadro de grave situação de desigualdade social. Como afirma Pochmann (2010, p. 4), "o Estado brasileiro estava enfraquecido por anos de desmonte de suas estruturas e a privatização de boa parte de suas funções". O autor defende que, a partir de 2003, o Brasil se transformaria em um dos principais países no cenário

\footnotetext{
${ }^{1}$ Além do Programa Bolsa Família, importa ressaltar que foi lançado um grande e significativo número de programas sociais, dentre os quais se destacam: Programa Minha Casa Minha Vida, Luz para Todos, Brasil Sem Fronteiras, Programa Universidade para Todos, Programa de Aquisição de Alimentos, os quais tiveram considerável importância socioeconômica, sobretudo devido ao forte impacto nas regiões mais pobres do país.
} 
internacional, com uma política externa direcionada aos interesses nacionais, buscando mudar a histórica desigualdade global nas relações norte-sul. O país pôde retomar níveis de crescimento econômico que não eram alcançados há muitos anos, com a geração de milhões de novos empregos com carteira assinada.

O governo Lula reconheceu a necessidade de programas sociais a serem implementados na sociedade brasileira, e, dentre as diversas bandeiras progressistas apontadas em seu discurso, estavam: i) o combate à fome e à miséria; ii) o combate ao racismo e às desigualdades raciais; iii) o aprofundamento dos avanços na área da saúde e de assistência social; iv) o crescimento da taxa de cobertura da Previdência Social; v) a promoção do desenvolvimento nacional mediante a integração das políticas públicas com o mercado de trabalho; vi) a implementação de uma efetiva política de desenvolvimento urbano; vii) a contínua melhoria da qualidade do ensino (COBO, 2012, p. 168-169).

Fagnani (2011), ao fazer uma análise dos primeiros anos do governo Lula (20032005), explica que o quadro de tensão existente refletia na indefinição da estratégia social de Lula, inicialmente ancorada no Programa Fome Zero, logo substituído pelo Programa Bolsa Família.

Sobre o Programa Fome Zero, há de se observar que as políticas que o envolviam articulavam necessariamente ações emergenciais e estruturais, rompendo com falsas dicotomias baseadas na separação entre o econômico e o social. Além da transferência direta de renda, por meio do cartão alimentação, o Fome Zero atuava nas seguintes áreas: reforma agrária, fortalecimento da agricultura familiar, programas de desenvolvimento territorial, programas de geração de trabalho e renda, desoneração tributária dos alimentos básicos, distribuição de alimentos, merenda escolar, programa de alimentação do trabalhador, produção para o consumo próprio, bancos de alimentos, restaurantes populares, cozinhas comunitárias e construção de cisternas para armazenamento de água (SILVA; GROSSI; FRANÇA, 2010).

O Programa Bolsa Família foi criado pela Medida Provisória no 132, de 20 de outubro de 2003, e reconhecido como Lei a partir de 9 de janeiro de 2004, sob o $\mathrm{n}^{\circ}$ 10.836, e regulamentado pelo Decreto ${ }^{\circ} 5.209$, de 17 de setembro de 2004 (SILVA; YAZBEK; GIOVANNI, 2014). Em paralelo, no ano de 2004, também foi aprovada uma nova Política Nacional de Assistência Social, na perspectiva de implementação do Sistema Único de Assistência Social (Suas), com a finalidade de regular e organizar, em âmbito nacional, todos os serviços, programas, projetos e benefícios socioassistenciais. Foi criado, ainda, o Ministério do Desenvolvimento Social e Combate à Fome (MDS), sendo unificadas, neste ministério, as áreas da Assistência Social (SNAS), Segurança Alimentar e Nutricional (Sesan) e Renda de Cidadania (Senarc) (MDS, 2007).

De uma maneira geral, o Programa Bolsa Família articula-se a partir de três aspectos básicos: i) ampliação dos serviços de saúde, educação e nutrição, mediante os 
mecanismos de condicionalidades; ii) integração dos programas de transferência de renda com os demais programas de assistência e iii) proteção social. Campello (2017, p. 11), ressalta que "o Bolsa Família é muito conhecido pelo aspecto da transferência de renda. Só que as condicionalidades compõem a dimensão mais transformadora do programa e que têm como premissa o rompimento intergeracional da pobreza". A condicionalidade é determinada pelo responsável pela família e diz respeito aos seguintes itens: i) manutenção das crianças em idade escolar frequentando as escolas; ii) sistema de vacinação das crianças atualizado; iii) obrigatoriedade de acompanhamento pré-natal para mulheres grávidas; iv) promoção da alfabetização nos casos em que há analfabetos adultos entre os membros da família beneficiada (SOARES; SÁTYRO, 2010).

Os critérios de elegibilidade do Bolsa Família baseiam-se na renda familiar total e na presença de crianças e jovens na família. O Bolsa Família divide-se em duas modalidades de benefícios: a primeira é o benefício básico, destinado às famílias que se encontram em situação de extrema pobreza; a segunda refere-se aos benefícios variáveis, destinados às famílias em situação de pobreza e que, em sua composição, contemplem gestantes, nutrizes, crianças entre zero e 12 anos ou adolescentes de até 17 anos. As famílias cuja renda per capita é inferior à linha de pobreza extrema têm direito a um benefício fixo, independentemente do número de pessoas que as compõem, além de terem também direito ao mesmo benefício variável das famílias cuja renda esteja entre as linhas de pobreza e pobreza extrema.

Para ser beneficiário do programa, é necessário que a família esteja cadastrada no CadÚnico (Cadastro Único). A coleta das informações dadas pela família é de responsabilidade do gestor municipal do programa, o que permite uma agilidade maior na obtenção dos dados. Essa facilidade é reflexo da maior interação entre os entes federativos - município, estado e União. $\mathrm{O}$ atendimento às condicionalidades é que permitirá a manutenção da família no Programa.

O tripé Bolsa Família, aumento do salário-mínimo e expansão do crédito ${ }^{2}$ é, para Singer (2012, p. 40), muito mais que uma simples “ajuda aos pobres", pois, não somente possui a capacidade de aumentar o padrão de consumo de pessoas de baixa renda (como atesta o acesso de 29 milhões à "classe C” entre 2003 e 2009), mas porque sugere um caminho de manutenção da estabilidade com expansão do mercado interno.

O Gráfico 1 mostra a evolução no número de beneficiários no Brasil, no período de 2004 a 2015. Observa-se que houve um aumento gradual no total de benefícios concedidos ao longo dos anos 2004 e 2013, quando ultrapassaram a marca dos 14

\footnotetext{
${ }^{2}$ Embora autores como Lavinas (2015) e Sestelo (2017) alertem para o fato de que o movimento de expansão de crédito agravou o nível de endividamento médio das famílias, revelando a financeirização das políticas sociais, entende-se que esta condição é inerente ao regime neoliberal que, desde os anos 1990, tem se expressado de forma mais aguda pela lógica da financeirização do capital (HARVEY, 2008).
} 
milhões, o que representa um aumento de 114,34\% em relação ao primeiro ano de comparação. Destaca-se, ainda, que nos dois anos seguintes houve uma leve redução no montante de beneficiários, mas não o suficiente para retornar ao patamar de 2012 ou de anos anteriores.

Gráfico 1 - Programa Bolsa Família, número de benefícios (dez.), 2004-2015

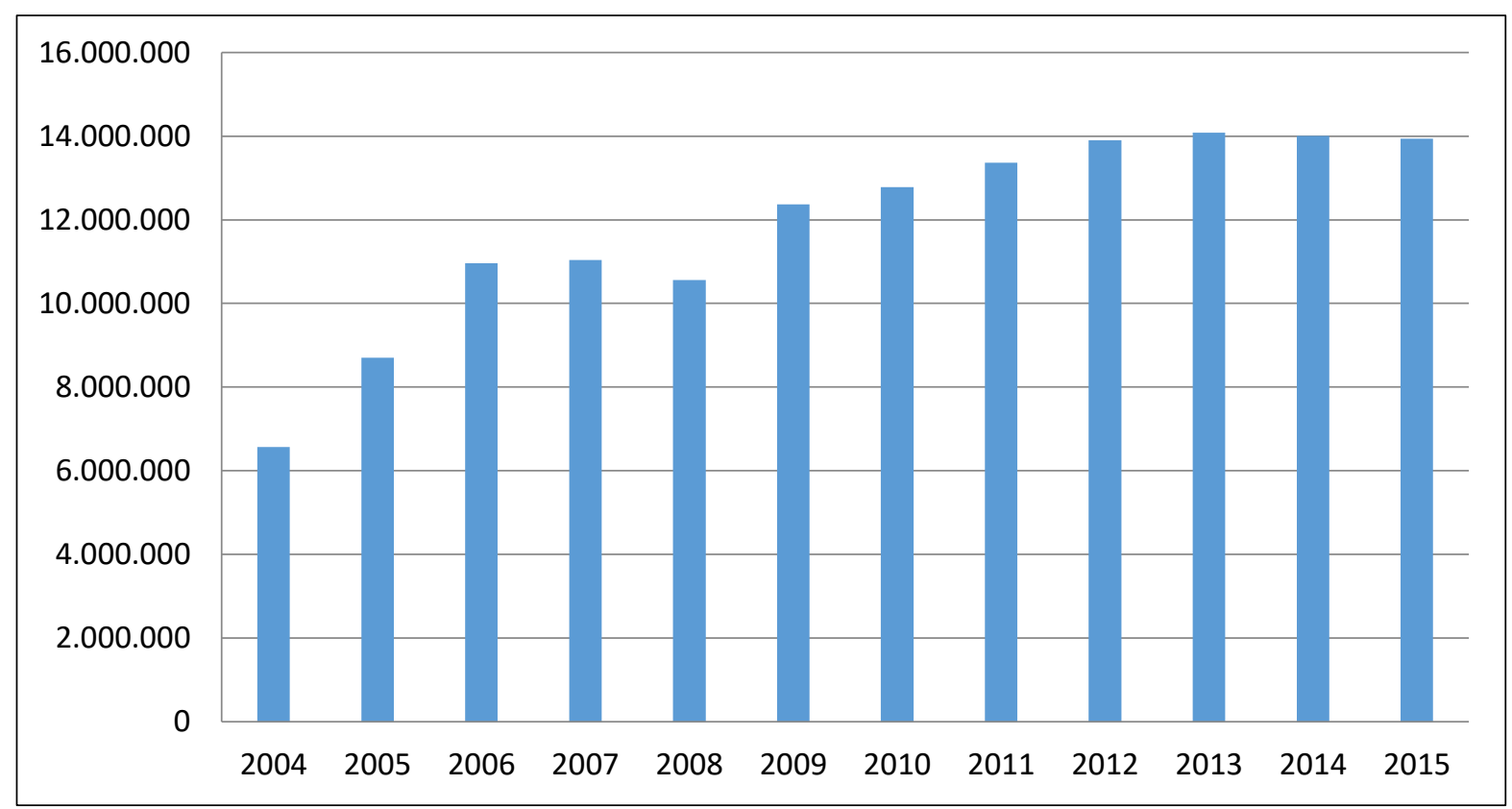

Fonte: Elaboração própria com base em dados do MDS, 2017.

Em consonância com os benefícios concedidos, observa-se no Gráfico 2 que foi significativa a mensuração do volume de recursos aplicados pelo Governo Federal em termos do Programa Bolsa Família, cujas despesas integram os dispêndios sociais nos anos de 2004 a 2015. Como se pode verificar, ao longo desse período, o montante de recursos liberados por meio do Programa Bolsa Família cresceu 629,22\%, uma média de 57\% a.a. 
Gráfico 2 - PBF, valor dos benefícios, acumulado no ano, em R\$, 2004-2015

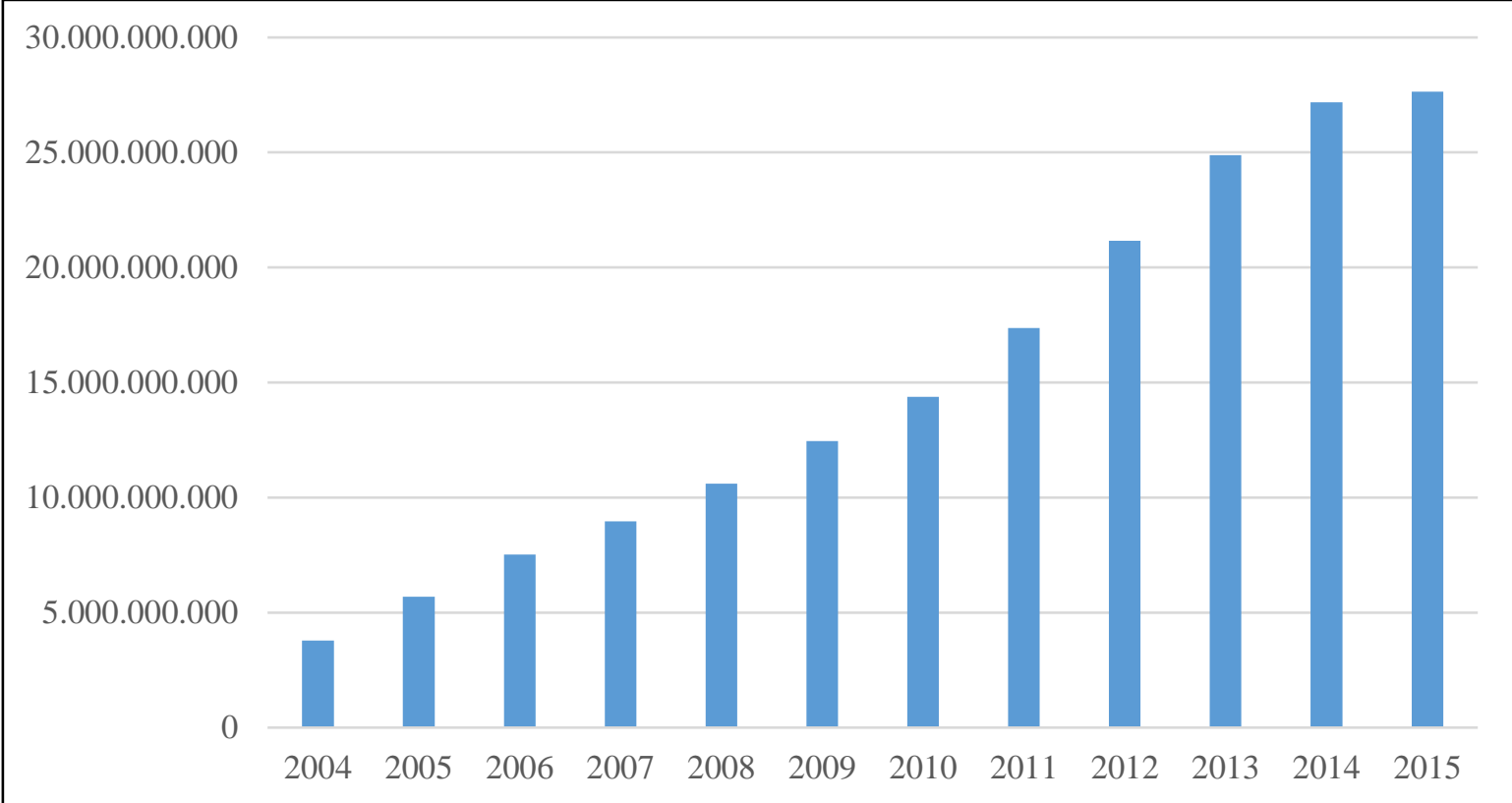

Fonte: Elaboração própria com base em microdados do IPEA-DATA, 2017.

Para o total de domicílios que viviam em miséria extrema, o Gráfico 3 aponta uma queda de 58,84\% no período estudado, passando de 5.533 .843 em 2003 para 2.277.971 domicílios em 2014, ou seja, em 10 anos, a redução da extrema pobreza foi, em média, 5,88\% a.a. A redução da pobreza por domicílios também foi significativa $(53,41 \%)$, com queda gradativa no período, alcançando 6.450 .482 unidades em 2014 contra 13.844.173 em 2003. 
Gráfico 3 - Pobreza e extrema pobreza, por domicílios, 2001-2014

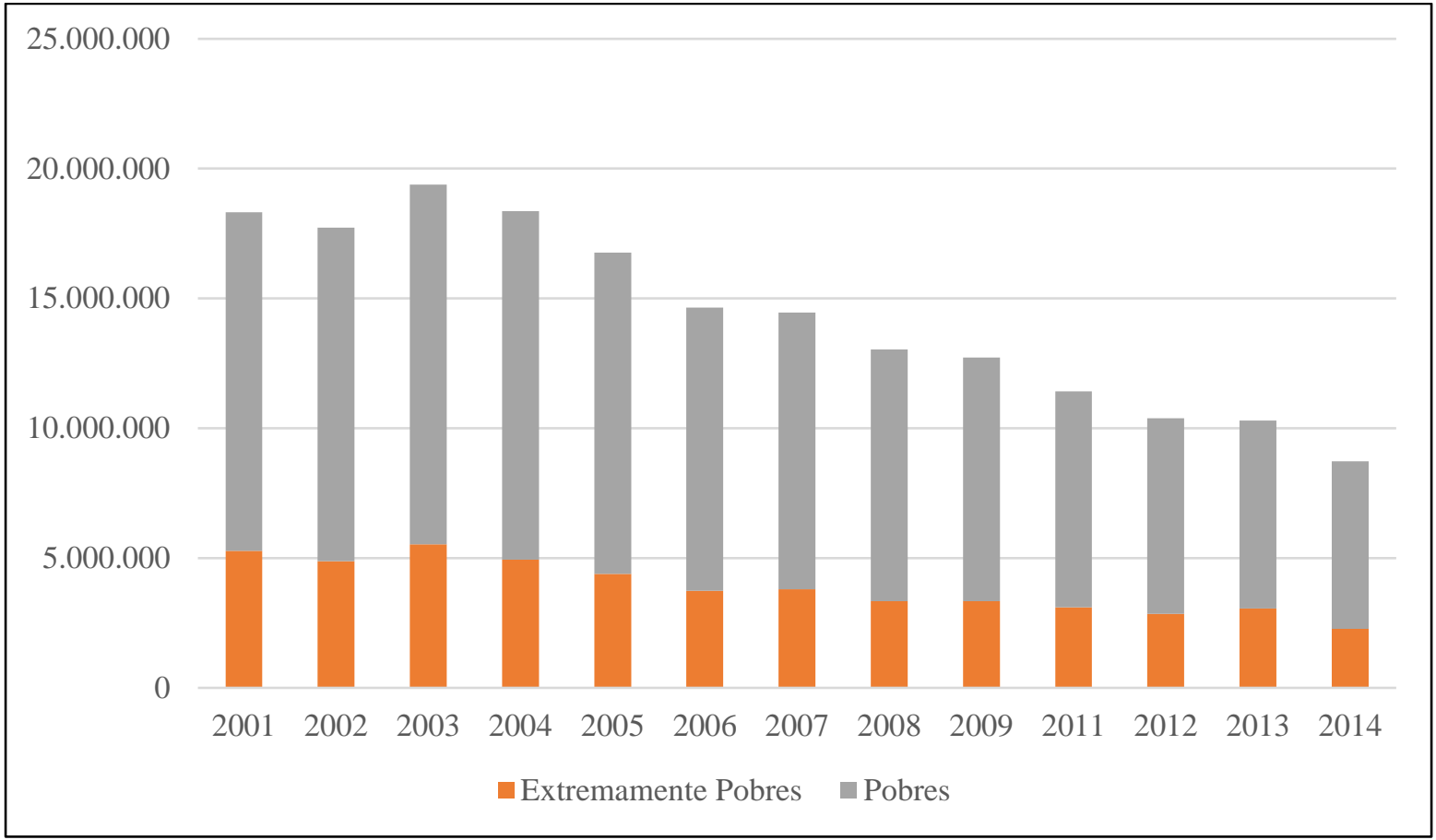

Fonte: Elaboração própria com base em dados do IPEA, 2014.

A partir dos dados apresentados, é possível inferir que a territorialização do PBF no Brasil tenha interrompido o alastramento da extrema pobreza, criando possibilidades mínimas de sobrevivência à população, pois, sem o programa, essas famílias não teriam condições financeiras para comprar nem mesmo a alimentação básica, ficando vulneráveis à fome.

A queda da pobreza e extrema pobreza reflete diretamente no coeficiente de Gini ${ }^{3}$, que apresentou declínio de forma acentuada logo no início do governo Lula. Nesse sentido, o Gráfico 4 apresenta, de maneira comparativa, o nível de desigualdade de renda, entre os anos de 2003 e 2014, no Brasil, a partir do índice de Gini, que é a medida de desigualdade de renda mais comumente utilizada. O que se observa é uma redução de $11,15 \%$ no grau de concentração de renda no país, quando o Gini caiu de 0,583 em 2004 para 0,518 no ano de 2014.

\footnotetext{
${ }^{3}$ Mede o grau de desigualdade na distribuição da renda domiciliar per capita entre os indivíduos. Seu valor pode variar, teoricamente, desde 0, quando não há desigualdade (as rendas de todos os indivíduos têm o mesmo valor), até 1, quando a desigualdade é máxima (apenas um indivíduo detém toda a renda da sociedade, sendo a renda de todos os outros indivíduos nula). Série calculada a partir das respostas à Pesquisa Nacional por Amostra de Domicílios (PNAD/IBGE).
} 
Gráfico 4 - Desigualdade de renda, coeficiente de Gini, Brasil, 2003-2014

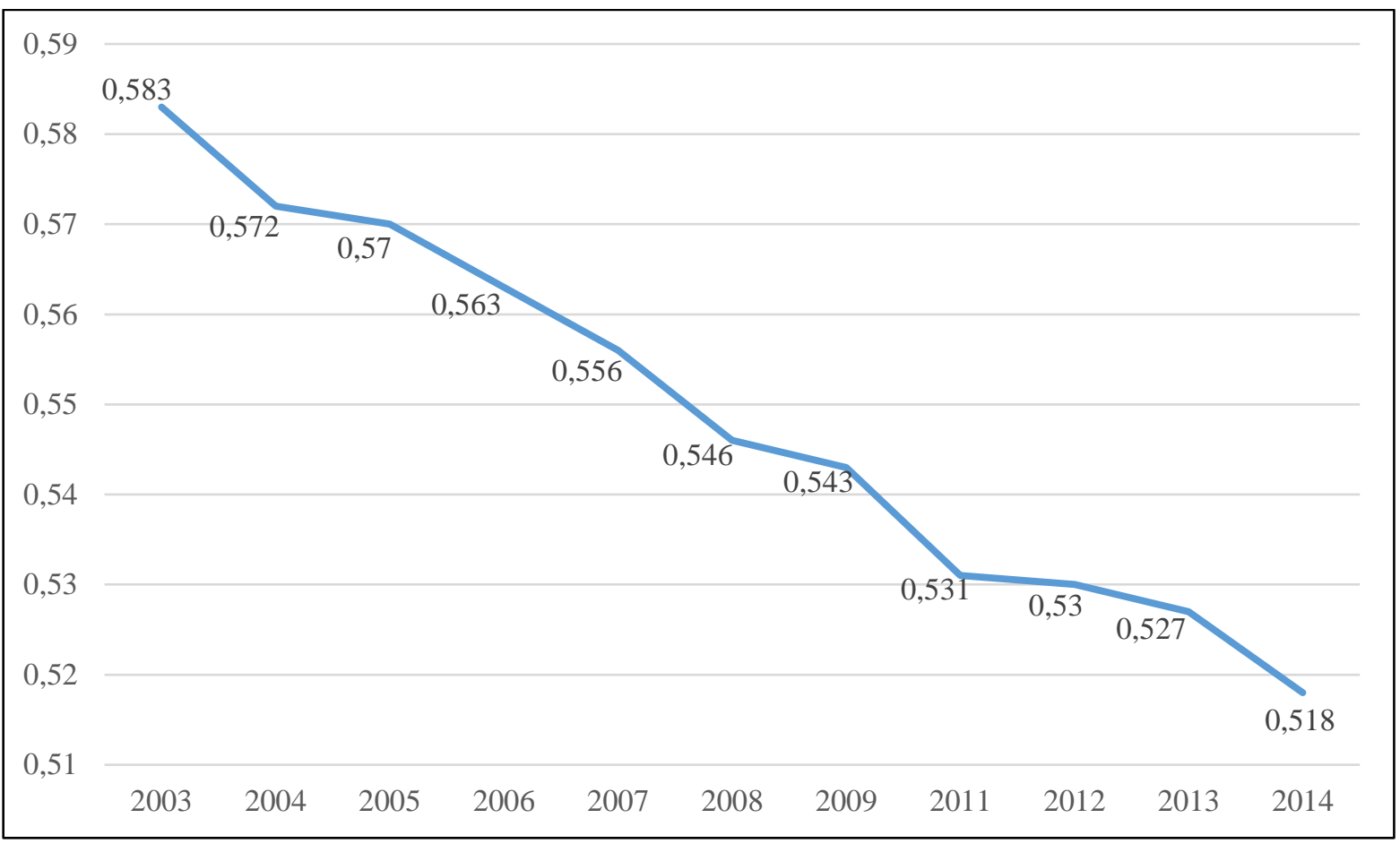

Fonte: Elaboração própria com base em dados do IPEADATA, 2016.

Campello (2017), usando os dados da Pesquisa Nacional por Amostra de Domicílios (PNAD) de 2002 a 2015, mostra que o crescimento real da renda do conjunto da população chegou a $38 \%$, sendo que esse crescimento foi ainda mais acentuado entre os mais pobres. De acordo com a autora, a renda dos $20 \%$ mais pobres cresceu quase quatro vezes mais rápido que a dos $20 \%$ mais ricos.

Estudos do IPEA (2012) e Fagnani (2014) revelam que, entre 2003 e 2012, a desigualdade social entre os assalariados declinou de forma expressiva: o rendimento médio real mensal dos trabalhadores subiu cerca de $30 \%$, enquanto, para os $20 \%$ mais pobres, o crescimento foi superior a $70 \%$. A elevação da renda do trabalho respondeu por cerca de $60 \%$ da queda da desigualdade social, a Seguridade Social contribuiu com $27 \%$, e o PBF, com $13 \%$.

Ademais, cabe destacar que, entre 2003 e 2015, houve um notável crescimento do salário-mínimo nominal, com efeitos positivos para a demanda agregada e para a distribuição de renda, contribuindo para a redução da desigualdade nos rendimentos do trabalho. O Gráfico 5 mostra que, no período em foco, o salário-mínimo aumentou 242,60\% (uma elevação média anual de 18,66\%), quando passou de mais de $\mathrm{R} \$ 230,00$ em 2003 para quase $\mathrm{R} \$ 790,00 \mathrm{em} 2015$. 
Gráfico 5 - Salário-mínimo nominal anual, em R\$, 2003-2015

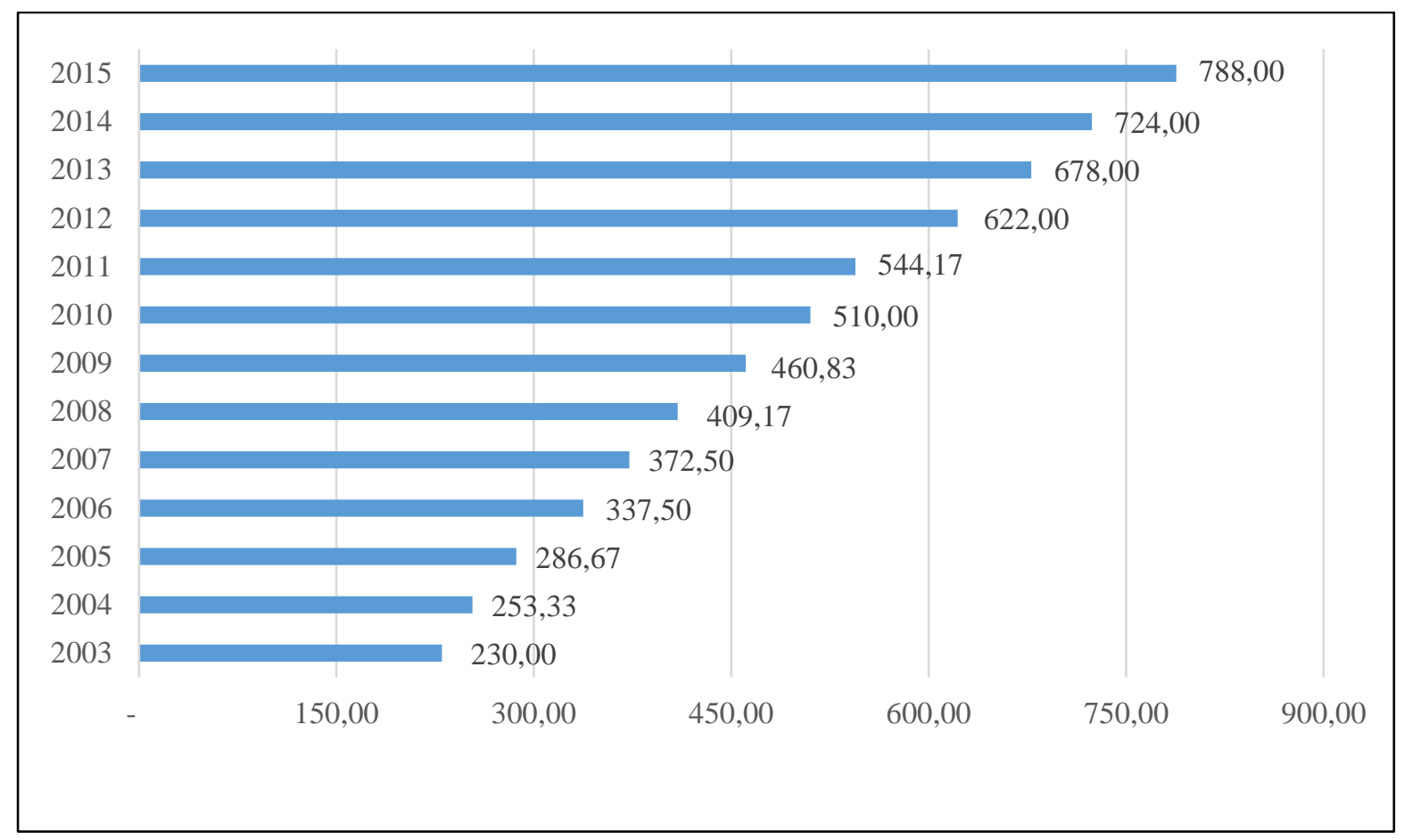

Fonte: Elaboração própria com base em dados do DIEESE, 2019.

Conforme já mencionado, a pobreza não reflete apenas a privação do acesso à renda monetária. Esse pensamento também é conduzido por Campello (2017, p. 19) quando diz que "a manutenção da desigualdade em educação é um dos fatores que mais determina a dinâmica de exclusão e a perpetuação da pobreza". A autora explica que a melhoria da renda - por meio da valorização do salário-mínimo, aposentadorias e, principalmente, do Bolsa Família — foi determinante para aumentar o acesso à educação, haja vista que o perfil predominante das famílias pobres é formado por pessoas jovens com filhos em idade escolar, além do que parte destas crianças estava no trabalho infantil ou privada do acesso à escola.

No caso do Programa Bolsa Família, esperava-se que a condicionalidade referente à educação reduzisse os indicadores de evasão, permitindo melhores médias de frequência e aprovação, bem como menor defasagem idade-série para as crianças das famílias beneficiárias. Com base nos dados da Tabela 1, é possível inferir que, quando se considera o período de 2001 a 2014, o acompanhamento da frequência escolar como condicionalidade do Bolsa Família apresentou-se efetivo em seu propósito. Ressalta-se que não foram identificados dados para o ano de 2010. 
Tabela 1 - Frequência escolar, por classe de idade, em \%, 2001-2014

\begin{tabular}{ccccccc}
\hline & \multicolumn{2}{c}{$\mathbf{5}$ a $\mathbf{6}$ anos } & \multicolumn{2}{c}{$\mathbf{7}$ a 14 anos } & \multicolumn{2}{c}{ 15 a 17 anos } \\
\cline { 2 - 7 } Ano & Homens & Mulheres & Homens & Mulheres & Homens & Mulheres \\
\hline 2001 & 75,53 & 77,06 & 96,27 & 96,68 & 82,11 & 80,07 \\
2002 & 76,13 & 78,33 & 96,63 & 97,26 & 81,30 & 81,66 \\
2003 & 78,04 & 79,42 & 96,89 & 97,49 & 81,98 & 82,75 \\
2004 & 79,54 & 82,73 & 96,76 & 97,36 & 81,28 & 82,40 \\
2005 & 81,13 & 81,78 & 97,03 & 97,57 & 81,14 & 82,10 \\
2006 & 83,98 & 85,03 & 97,46 & 97,80 & 81,48 & 82,68 \\
2007 & 85,99 & 85,96 & 97,37 & 97,75 & 81,29 & 82,93 \\
2008 & 87,72 & 87,63 & 97,73 & 98,11 & 83,44 & 84,78 \\
2009 & 89,08 & 88,98 & 97,78 & 98,29 & 84,15 & 86,26 \\
2011 & 90,61 & 91,54 & 98,46 & 98,57 & 83,06 & 84,39 \\
2012 & 91,52 & 91,51 & 98,47 & 98,57 & 83,59 & 84,75 \\
2013 & 92,58 & 93,36 & 98,49 & 98,81 & 83,99 & 84,68 \\
2014 & 93,44 & 93,89 & 98,55 & 98,85 & 84,10 & 84,44 \\
\hline
\end{tabular}

Fonte: IPEA, 2014.

De acordo com a Tabela 1, fica evidente que no período de 2001 a 2014 houve aumento na frequência escolar para todas as faixas etárias consideradas. O destaque foi entre crianças na faixa etária de cinco a seis anos, quando se observou uma ampliação de 23,71\% na frequência escolar dos meninos aí inseridos, e de 21,84\% na frequência das meninas; para a faixa de 15 a 17 anos, os acréscimos foram discretos, na ordem de $2,42 \%$ na frequência dos homens, e 5,46\% na das mulheres; por fim, na faixa etária de sete a 14 anos, que já detinha o posto da que apresentava a maior frequência desde 2001, a elevação foi tímida, respectivamente, 2,37\% e $2,24 \%$.

Outra contribuição menos explícita, mas não menos importante, na medida em que ocorreu aumento da renda das famílias, foi a possibilidade de haver um menor comprometimento no percentual dos gastos com alimentação, de modo que parte dos recursos acabaram tendo como destino a aquisição de bens de consumo duráveis, conforme revelam os dados do Gráfico 6. 
Gráfico 6 - Bens duráveis em domicílios, em \%, 2003-2015

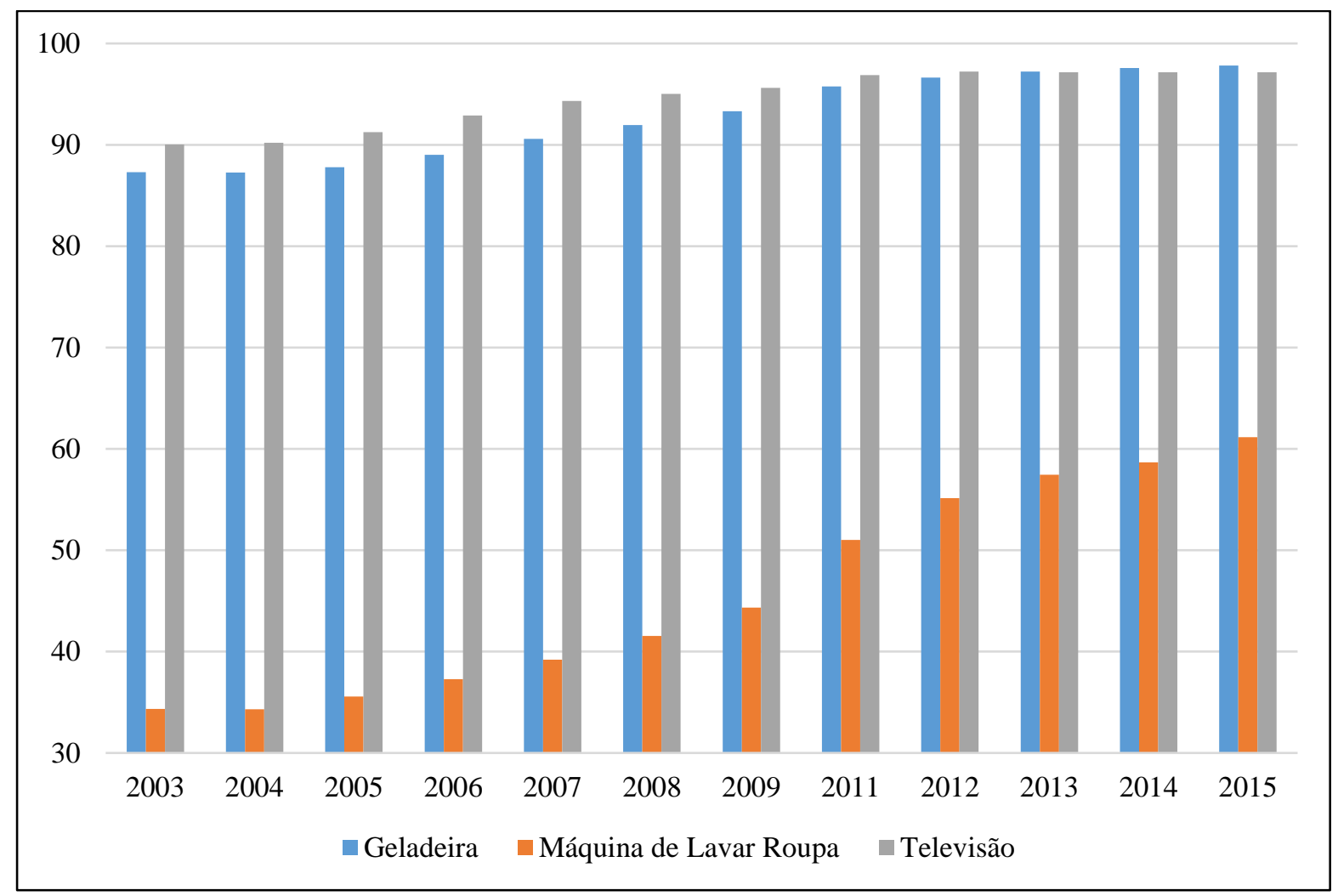

Fonte: Elaboração própria com base nos dados do IBGE/PNAD, 2015.

Com relação aos dados apresentados no Gráfico 6, observa-se que, no ano de 2003, cerca de 87\% dos lares já possuíam geladeira, e 90\% tinham TV; em 2015, esses percentuais ultrapassaram a marca de $97 \%$, o que representou um crescimento de $12,07 \%$ na participação dos domicílios com geladeiras e de 7,91\% nos lares com TV. O maior salto, contudo, pertence ao bem máquina de lavar roupa, que, em 2003 , apresentava percentual abaixo de $35 \%$, atingindo os $61,14 \%$ dos lares em 2015, ou seja, uma elevação de 78,04\%. Por trás desses dados, além da evidente possibilidade de aquisição dos eletrodomésticos, o que tem relação também com a expansão do crédito, estão programas como o Luz para Todos, que universalizou o acesso à energia elétrica.

Em relação ao acesso dos domicílios brasileiros a telefone celular, microcomputador e internet, ainda se observa uma falta de democratização desses bens. Em 2015, o percentual de lares com celular não chegava a $60 \%$, enquanto os que possuíam microcomputador e/ ou internet era inferior a 50\%, como mostra o Gráfico 7. 
Gráfico 7 - Bens em domicílios, em \%, 2003-2015

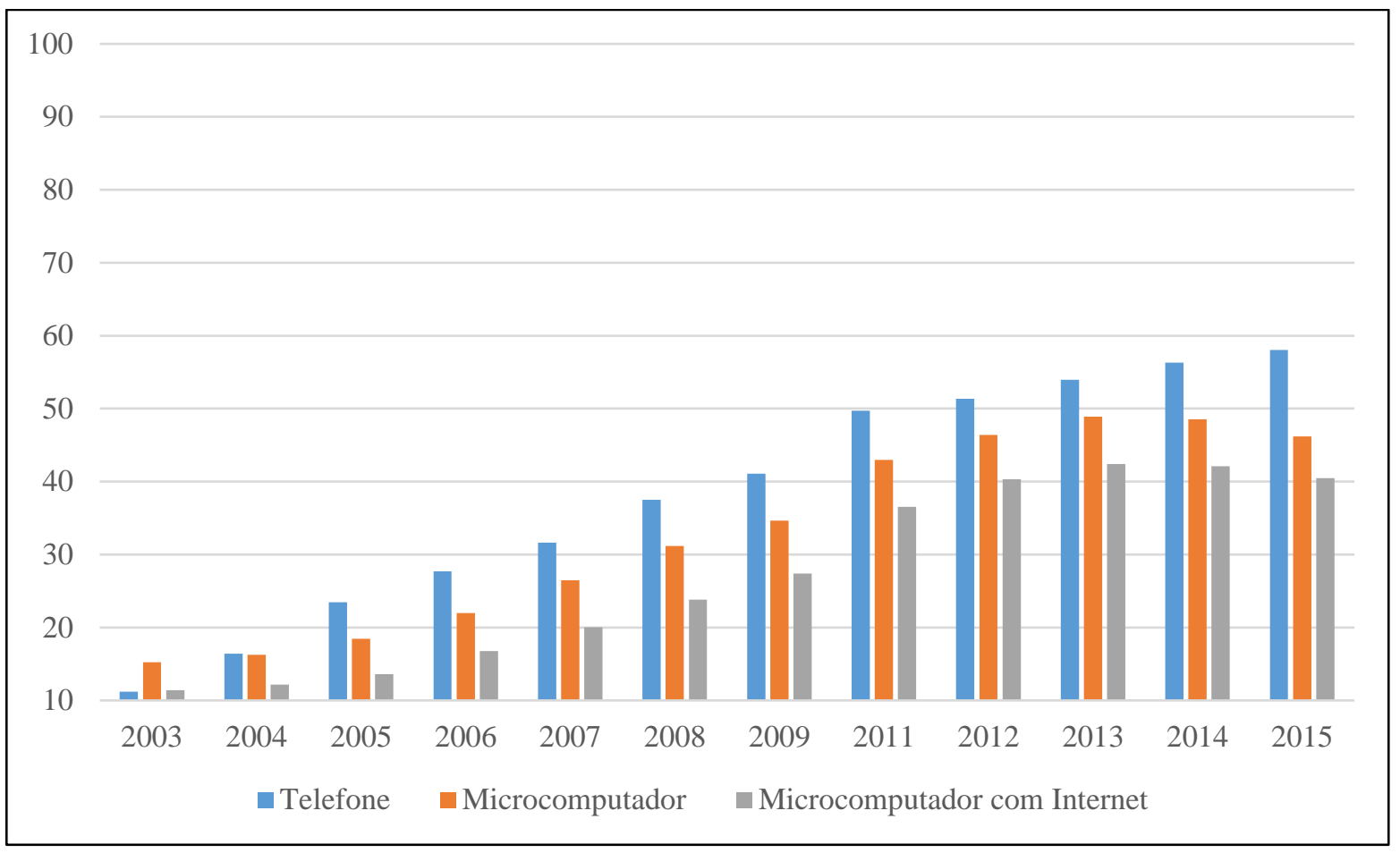

Fonte: Elaboração própria com base nos dados do IBGE/PNAD, 2015.

Contudo, mesmo apresentando percentuais menores do que os vistos no Gráfico 6, é inegável o crescimento acelerado na participação dos lares, que passaram a possuir tais bens e/ou serviços no período estudado: o percentual de domicílios com acesso a aparelho celular saiu de 11,19\% em 2003 para 58,02\% em 2015. Ou seja: ao longo desse período, a ampliação na participação foi de 418,5\%, colocandoo como o bem mais possuído dentre os três listados. Em seguida, observa-se o aumento na ordem de $254 \%$ para os lares com microcomputador com internet, que passaram de 11,42\% em 2003 para mais de $40 \%$ em 2015. Por fim, os domicílios com microcomputador também subiram de 15,25\% em 2003 para 46,18\% em 2015, um salto de $203 \%$ para o período.

A análise dos gráficos apresentados torna evidente a queda nos níveis de pobreza e extrema pobreza, como também apresenta uma melhora na distribuição de renda no período de 2003 a 2015. É evidente que este mérito não é somente das políticas de transferências de renda, a exemplo do Programa Bolsa Família, pois essa mudança é explicada também pelo aumento real do salário-mínimo, a crescente formalização do mercado de trabalho, a incorporação dos mais pobres ao orçamento federal, mediante políticas de inclusão social e distribuição efetiva de renda e acesso ao crédito. 


\section{Considerações finais}

O combate à pobreza e à desigualdade social constitui-se como um objetivo político importante em um sistema de proteção social, uma vez que este deve prover igualdade de acesso e de oportunidades a todos os indivíduos, assegurando, assim, que seus benefícios alcancem toda a população e, em particular, os grupos mais vulneráveis.

Nesse sentido, este artigo procurou demonstrar que as transferências de renda têm um papel importante, tendo em vista que a desigualdade social tende a ser determinada, principalmente, pela distribuição desigual da renda, embora existam outros fatores como o crescimento desigual da economia, a má formação educacional, investimentos mal distribuídos, disparidades regionais etc.

Embora os programas de transferência de renda no Brasil remetessem a um período anterior à Constituição Federal de 1988, é inegável concluir que os mandatos dos presidentes Lula e Dilma não podem ser compreendidos como uma repetição dos governos que lhes antecederam. O Brasil, a partir de 2003, ainda que mantendo níveis de desigualdade, começou a reverter um ciclo histórico de injustiça social, marcado pela crescente exclusão dos mais pobres e pela concentração de privilégios nos setores mais ricos da sociedade. Como demonstraram os gráficos apresentados, essa transformação é explicada pelo tripé Bolsa Família, elevação do salário-mínimo e acesso ao crédito, sendo que o PBF foi a base para a construção desse tripé.

Não é possível afirmar que nos governos de Lula e Dilma (2003-2016) tenha sido construído um efetivo Estado de Bem-Estar Social, mas o diferencial desses governos foi tentar compatibilizar crescimento econômico com medidas de distribuição de renda, simplesmente atendendo ao que preconiza a Constituição Federal de 1988 no tocante ao sistema de proteção social. Apesar do efeito colateral - o endividamento médio das famílias - fica evidente que as políticas públicas de assistência social implementadas nos períodos de gestão desses governos proporcionaram importantes ações de combate à pobreza, bem como favoreceram a redução da desigualdade social, mesmo que ainda não o suficiente quando comparado ao nível de proteção social verificado nos países desenvolvidos.

\section{Referências}

BRANDÃO, Carlos Antônio. Crise e rodadas de neoliberalização: impactos nos espaços metropolitanos e no mundo do trabalho no Brasil. Cadernos Metrópole, São Paulo, vol. 19, n. 38, p. 45-69, jan.-abr. 2017. 
BRASIL. Constituição da República Federativa do Brasil de 1988.

Brasília/DF: Presidência da República, 2016. Disponível em:

http://www.planalto.gov.br/ccivil_03/Constituicao/Constituiçao.htm. Acesso em: 1 jan. 2019.

BRESSER-PEREIRA, Luiz Carlos. A construção política do Brasil: sociedade, economia e Estado desde a Independência. São Paulo: Editora 34, 2013.

CABRERA, Cecilia Correa. Características e tendências dos Programas de Transferência de Renda na América Latina: destaque às experiências brasileira e peruana. 2015. 240f. Tese (Doutorado em Política Social) - Departamento de Serviço Social, Universidade de Brasília, Brasília, 2015.

CAMPELLO, Tereza. Faces da desigualdade no Brasil: um olhar sobre os que ficam para trás. Brasília/DF: FLACSO, 2017.

CAMPOS, André Cambier. Bem-estar social nos anos 1990 e 2000: traços estilizados da história brasileira (= Texto para discussão). Brasília; Rio de Janeiro: Ipea, 2015. Disponível em:

https://www.ipea.gov.br/portal/index.php?option=com_content\&view=article\&id $=2$ 4380:td-2025-bem-estar-social-nos-anos-1990-e-2000-tracos-estilizados-da-historiabrasileira\&catid $=344: 2015 \&$ directory $=1$. Acesso em: 23 jul. 2021.

COBO, Barbara. Políticas focalizadas de transferência de renda: contexto e desafios. São Paulo: Cortez, 2012.

DIEESE. Salário-mínimo nominal e necessário. 2019. Disponível em: https://www.dieese.org.br/analisecestabasica/salarioMinimo.html. Acesso em: 06 mai. 2020.

FAGNANI, Eduardo. Política social e desigualdade. Brasil: dois projetos em disputa. Le Monde Diplomatique Brasil. Edição n.84, 2014. Disponível em www.diplomatique.org.br/brasil-dois-projetos-em-disputa. Acesso em 20 de maio de 2018. 
FAGNANI, Eduardo. Notas sobre o desenvolvimento social recente no Brasil (= Texto para Discussão). Campinas: IE/UNICAMP, 2011, p. 1-9.

FIGUEIREDO, Joseane Gomes. Desigualdade social e capitalismo: os limites da igualdade sob a ordem burguesa. In: VI Jornada Internacional de Políticas Públicas. 2013, São Luiz do Maranhão. Anais [...]. São Luiz do Maranhão, 2013.

HARVEY, David. O neoliberalismo: história e implicações. São Paulo: Loyola, 2008.

IBGE. Pesquisa Nacional por Amostra de Domicílios: bens em domicílios. Rio de Janeiro: Instituto Brasileiro de Geografia e Estatística, 2015. Disponível em: https://sidra.ibge.gov.br/tabela/2249. Acesso em: 06 mai. 2020.

IPEA. Número de domicílios extremamente pobres.

Brasília. Instituto de Pesquisa Aplicada, 2014. Disponível em: www.ipea.gov.br. Acesso em: 09 jan 2021.

IPEA. A década inclusiva (2001 - 2011): desigualdade, pobreza e políticas de renda. Comunicados do IPEA n. 55. Brasília: IPEA, 2012. Disponível em www.ipea.gov.br. Acesso em 11 de fev. 2018.

IPEA-IPEADATA. Programa Bolsa Família: valor total dos benefícios em dezembro. Brasília: Instituto de Pesquisa Econômica Aplicada, 2016. Disponível em: http://www.ipeadata.gov.br/. Acesso em: 06 mai. 2020.

IPEA-IPEADATA. Programa Bolsa Família: valor total dos benefícios em dezembro. Brasília: Instituto de Pesquisa Econômica Aplicada, 2017. Disponível em: http://www.ipeadata.gov.br/. Acesso em: 06 mai. 2020.

IPEA-IPEADATA. Programa Bolsa Família: valor total dos benefícios em dezembro. Brasília: Instituto de Pesquisa Econômica Aplicada, 2014. Disponível em: http://www.ipeadata.gov.br/. Acesso em: 06 mai. 2020.

LAVINAS, Lena. Bolsa. Família e Bolsa-Banco: a financeirização do social. In: Insight Inteligência, 2015. Disponível em: http:/ / 
https://inteligencia.insightnet.com.br/bolsa-familia-e-bolsa-banco-afinanceirizacao-do-social/. Acesso em: 20 jul. 2021.

LAVINAS, Lena; VARSANO, Ricardo. Programas de garantia de renda mínima e ação coordenada de combate à pobreza. Rio de Janeiro: Instituto de Pesquisa Econômica Aplicada, 1998.

MAT'TEI, Lauro. Políticas sociais de enfrentamento da pobreza na América Latina: uma análise comparada entre Brasil e Argentina. Revista Katálysis, Florianópolis, vol. 18, n. 2, p. 222-230, jul.-dez. 2015. Disponível em: https:/ / www.scielo.br/scielo.php?pid=S1414-

49802015000200222\&script=sci_abstract\&tlng=pt. Acesso em: 12 abr. 2020.

MDS. Famílias beneficiárias do Programa Bolsa Família. Brasília: Ministério do Desenvolvimento Social e Combate à Fome, 2017.

MDS. Bolsa Família. Brasília: Ministério do Desenvolvimento Social e Combate à Fome, 2007. Disponível em: http://mds.gov.br/assuntos/bolsa-familia/o-que-e. Acessado em: 20 dez. 2016.

POCHMANN, Marcio. Desenvolvimento, trabalho e renda no Brasil: avanços recentes no emprego e na distribuição dos rendimentos. São Paulo: Fund. Perseu Abramo, 2010.

SESTELO, José Antonio de Freitas. A financeirização das políticas sociais e da saúde no Brasil do século XXI: elementos para uma aproximação inicial.

Economia e Sociedade, Campinas, vol. 26, Número Especial, p. 1097-1126, dez. 2017.

SILVA, José Graziano da; GROSSI, Mauro Eduardo Del; FRANÇA, Caio Galvão de (Org.) Fome Zero: a experiência brasileira (= NEAD). Brasília: MDA, 2010.

SILVA, Maria Ozanira da. A trajetória dos programas de transferência de renda e seus desafios atuais: articulação com políticas estruturantes e unificação. Revisa Pensar, Belo Horizonte, abr.-jun. 2006. Disponível em:

https:// repositorio.ufma.br/jspui/bitstream/1/162/1/A \%20trajetoria $\% 20 \mathrm{dos} \% 2$ 
Oprogramas $\% 20$ de $\% 20$ transferencia $\% 20$ de $\% 20$ renda $\% 20 \mathrm{e} \% 20$ seus $\% 20$ desafios $\%$ 20atuais.pdf. Acesso em: 12 abr. 2020.

SILVA, Maria Ozanira da; LIMA, Valeria Ferreira Santos de Almeida. "Antecedentes e contextualização: trajetória de desenvolvimento do Bolsa Família”. In: SILVA, Maria Ozanira da Silva (Org.) O Bolsa Família: verso e reverso. Campinas: Papel Social, 2016.

SILVA, Maria Ozanira da; YAZBEK, Maria Carmelita; GIOVANNI, Geraldo di. A política social brasileira no século XXI: a prevalência dos programas de transferência de renda. São Paulo: Cortez, 2014.

SINGER, André. Os sentidos do lulismo: reforma gradual e pacto conservador. São Paulo: Companhia das Letras, 2012.

SOARES, Sergei; SÁTYRO, Natália. O Programa Bolsa Família: desenho institucional, impactos e possibilidades futuras. In: CASTRO, Jorge Abrahão de; MODESTO, Lúcia (Org.) Bolsa Família 2003-2010: avanços e desafios. Brasília: IPEA, 2010, p. 27-55.

SOUZA, Ana Patrícia dos Anjos. Os direitos sociais na era Vargas: a previdência social no processo histórico de constituição dos direitos sociais no Brasil. In: II JORNADA INTERNACIONAL DE POLÍTICAS PÚBLICAS, 2005, São Luís. Anais... São Luís: UFMA, 2005, p. 1-7.

SUPLICY, Eduardo Matarazzo. Renda de cidadania: a saída é pela porta. 7 ed. São Paulo: Cortez, 2013.

THOMÉ, Débora. O Bolsa Família e a social-democracia. Rio de Janeiro: FGV, 2013. 
Data de submissão: 05/06/2020

Data de aprovação: 06/08/2021

Revisão: Daniela Matthes (português), Anderson de Miranda Gomes (inglês) e Yanet María Reimondo Barrios (espanhol).

Vanuza Maria Pontes Sena

Departamento de Ciências Econômicas / Universidade do Estado do Rio Grande do Norte (Campus Avançado de Pau dos Ferros)

BR 405, km 3 - Arizona

59900-000 Pau dos Ferros/RN, Brasil

Orcid: http://orcid.org/0000-0003-0484-6807

E-mail: vanuzapontes@gmail.com

Cristina Pereira de Aranjo

Programa de Pós-Graduação em Desenvolvimento Urbano / Universidade Federal de Pernambuco

Avenida da Arquitetura, s/n - Cidade Universitária

50740-550, Recife/PE, Brasil

Orcid: http://orcid.org/0000-0001-9986-5394

E-mail: cristina.pereira@ufpe.br 
Vanuza Maria Pontes Sena e Cristina Pereira de Aranjo 